\title{
Evaluation of the combined use of adiponectin and C-reactive protein levels as biomarkers for predicting the deterioration in glycaemia after a median of 5.4 years
}

\author{
K. L. Ong • A. W. K. Tso • A. Xu • L. S. C. Law • M. Li • \\ N. M. S. Wat • K. A. Rye • T. H. Lam • B. M. Y. Cheung • \\ K. S. L. Lam
}

Received: 19 April 2011 / Accepted: 6 June 2011 /Published online: 5 July 2011

(C) The Author(s) 2011. This article is published with open access at Springerlink.com

\begin{abstract}
Aims/hypothesis Hypoadiponectinaemia and raised C-reactive protein (CRP) level are obesity-related biomarkers associated with glucose dysregulation. We evaluated the combined use of these two biomarkers in predicting the deterioration of glycaemia in a prospective study after a median of 5.4 years.

Methods In total 1,288 non-diabetic participants from the Hong Kong Cardiovascular Risk Factor Prevalence Study-2, with high-sensitivity CRP (hsCRP) and total adiponectin levels measured were included. OGTT was performed in all participants. Two hundred and six participants had deterioration of glycaemia at follow-up, whereas 1,082 participants did not.
\end{abstract}

Electronic supplementary material The online version of this article (doi:10.1007/s00125-011-2227-0) contains peer-reviewed but unedited supplementary material, which is available to authorised users.

K. L. Ong • A. W. K. Tso • A. Xu • L. S. C. Law $\cdot$ N. M. S. Wat

B. M. Y. Cheung $(\bowtie) \cdot K$. S. L. Lam $(\bowtie)$

Department of Medicine, The University of Hong Kong,

Queen Mary Hospital,

102 Pokfulam Road,

Pokfulam, Hong Kong Special Administrative Region,

The People's Republic of China

e-mail: mycheung@hku.hk

e-mail: ksllam@hku.hk

K. L. Ong $\cdot$ K. A. Rye

Lipid Research Group, Heart Research Institute,

Sydney, NSW, Australia

A. W. K. Tso - A. Xu • B. M. Y. Cheung • K. S. L. Lam Research Centre of Heart, Brain, Hormone and Healthy Aging,

The University of Hong Kong, Queen Mary Hospital, 102 Pokfulam Road,

Pokfulam, Hong Kong Special Administrative Region,

The People's Republic of China
Results Baseline age, hsCRP and adiponectin levels were significant independent predictors of the deterioration of glycaemia in a Cox regression analysis after adjusting for baseline age, sex, BMI, hypertension, triacylglycerols, $2 \mathrm{~h}$ post-OGTT glucose and homeostasis model assessment of insulin resistance index (all $p<0.01$ ). The introduction of hsCRP or adiponectin level to a regression model including the other biomarker improved the prediction of glycaemic progression significantly in all participants, especially in women (all $p<0.01$ ). The combined inclusion of the two biomarkers resulted in a modest improvement in model discrimination, compared with the inclusion of either one alone. Among participants with impaired fasting glucose/ impaired glucose tolerance (IFG/IGT) at baseline, hsCRP

A. Xu

Department of Pharmacology, The University of Hong Kong,

Hong Kong Special Administrative Region,

The People's Republic of China

M. Li

Department of Cardiology, the First Affiliated Hospital with

Nanjing Medical University,

Nanjing, The People's Republic of China

\section{T. H. Lam}

Department of Community Medicine and School of Public Health, The University of Hong Kong,

Hong Kong Special Administrative Region,

The People's Republic of China 
and adiponectin levels were not predictive of progression or improvement of glycaemic status.

Conclusions/interpretation Adiponectin and hsCRP levels are independent factors in predicting the deterioration of glycaemia, supporting the role of adiposity-related inflammation in the development of type 2 diabetes. Their combined use as predictive biomarkers is especially useful in women, but not in participants with IFG/IGT.

Keywords Adiponectin - Biomarker. C-reactive protein . Glycaemia

$\begin{array}{ll}\text { Abbreviations } \\ \text { CRISPS } & \begin{array}{l}\text { Hong Kong Cardiovascular Risk Factor } \\ \text { Prevalence Study }\end{array} \\ \text { CRP } & \text { C-reactive protein } \\ \text { HMW } & \text { High molecular weight } \\ \text { hSCRP } & \text { High-sensitivity C-reactive protein } \\ \text { HOMA-IR } & \text { HOMA of insulin resistance index } \\ \text { IFG } & \text { Impaired fasting glucose } \\ \text { IGT } & \text { Impaired glucose tolerance } \\ \text { NGT } & \text { Normal glucose tolerance }\end{array}$

\section{Introduction}

The prevalence of obesity is increasing and has become a major global burden on public health. Obesity is known to cause the deterioration of glycaemia, leading eventually to diabetes. Adipose tissue has been recognised as an endocrine organ in addition to its role in lipid storage and mobilisation [1]. In obese individuals, there is an excess of ectopic fat deposition at undesirable sites such as liver, skeletal muscle and heart [1]. The excess adiposity is associated with dysregulated secretion of various adipokines [1]. Adiponectin is one of the most abundant and well-studied adipokines. It is secreted exclusively from adipose tissue with direct insulin-sensitising, anti-atherogenic and anti-inflammatory properties [2,3]. Circulating level of adiponectin is lower in individuals with obesity [4] and type 2 diabetes [5]. In prospective studies, hypoadiponectinaemia can predict the development of type 2 diabetes in Chinese [6], Pima Indians [7] and whites [8].

An increase in adipose tissue mass is often associated with inflammation due to macrophage infiltration. Chronic inflammation in adipose tissue contributes to the development of insulin resistance through increased secretion of inflammatory cytokines such as IL-6 and TNF- $\alpha$ from adipocytes and activated macrophages [3]. In humans, plasma level of C-reactive protein (CRP), a cytokine downstream of TNF- $\alpha$ and IL- 6 in the inflammatory cascade and a marker of chronic inflammation, correlates positively with body fat mass, visceral adipose tissue accumulation and plasma insulin [9]. In prospective studies, raised CRP levels, measured with a high-sensitivity assay (hsCRP), predict the development of type 2 diabetes in both Chinese [10] and white [11, 12] people.

Although previous studies have demonstrated that either hypoadiponectinaemia or raised hsCRP level could predict the deterioration of glycaemia $[6-8,10-12]$, it remains uncertain whether these two biomarkers are useful in predicting glycaemic progression in the general Chinese population, over and above conventional risk factors such as age, sex, BMI or waist circumference, insulin resistance and baseline plasma glucose. It is also not known whether the combined use of these two biomarkers could improve on the prediction of glycaemic progression, vs the use of either alone. Such studies in Chinese are especially indicated in view of ethnic differences in visceral adiposity and hsCRP level. Compared with white people, Asian people often have a greater degree of visceral adiposity and higher risk of type 2 diabetes for the same BMI [13], but have lower hsCRP level [14]. In fact, a recent study from the European Prospective Investigation of Cancer (EPIC)-Norfolk population-based cohort showed that the association of baseline hsCRP level with incident diabetes after a mean follow-up of 3.7 years could be due to the effect of confounding factors, including adiposity and adiponectin [15].

We hypothesised that the measurement of both adiponectin and hsCRP, which exert opposite effects on systemic inflammation $[2,3]$, will provide a better index of obesityrelated inflammatory changes, now recognised to play a key role in the pathogenesis of type 2 diabetes. Therefore, in this study, we examined, in a prospective study of unrelated, non-diabetic Chinese people, the combined use of the levels of these two biomarkers, adiponectin and hsCRP, in predicting the deterioration of glycaemia after a median interval of 5.4 years, and whether they can improve the prediction based on conventional risk factors.

\section{Methods}

Study participants The Hong Kong Cardiovascular Risk Factor Prevalence Study (CRISPS) is a population-based prospective cohort study of cardiovascular risk factors in Hong Kong Chinese [16]. In 1995-1996 (CRISPS-1), a random sample of 2,895 Hong Kong Chinese participants, representative of the general population, was recruited through random telephone numbers. In 2000-2004, 1,944 participants were followed up in CRISPS-2 [16]. The study protocol was approved by the Ethics Committee of the University of Hong Kong. All participants gave written consent.

Among 1,619 non-diabetic participants in CRISPS-2 (baseline), 1,307 participants had been followed up in 
CRISPS-3 in 2005-2008 with valid glycaemic status after a median follow-up period of 5.4 years $(6,706.3$ personyears). Among them, hsCRP and adiponectin levels were measured in 1,298 participants. After further excluding 10 participants with hsCRP level $>10 \mathrm{mg} / \mathrm{l}$, which was considered to reflect clinical inflammation, a total of 1,288 participants $(6,621.9$ person-years) were included in this analysis. There were 886 participants with their glycaemic status (normal glucose tolerance [NGT] or impaired fasting glucose $[\mathrm{IFG}] /$ impaired glucose tolerance [IGT]) remaining unchanged, 206 participants with deterioration of glycaemia (i.e. from NGT to IFG/IGT or diabetes, or from IFG/IGT to diabetes) and 196 participants with improved glycaemia (from IFG/IGT to NGT).

Variables of interest The study procedures in CRISPS, including the measurement of blood pressure, body weight, height and waist circumference on the assessment days, have been described previously [16]. OGTT was performed in all the included participants at both baseline and followup, except those taking glucose-lowering medication. Diabetes was defined as fasting glucose $\geq 7.0 \mathrm{mmol} / \mathrm{l}, 2 \mathrm{~h}$ glucose $\geq 11.1 \mathrm{mmol} / 1$ after OGTT or the use of glucoselowering medication [17]. IFG/IGT was defined as fasting glucose of 5.6-6.9 mmol/1 or $2 \mathrm{~h}$ post-OGTT glucose of $7.8-11.0 \mathrm{mmol} / 1$ in non-diabetic participants [17]. Total adiponectin (intra-assay and inter-assay coefficients of variation of $6.2-8.3 \%$ and $5.1-6.4 \%$ respectively) and hsCRP levels (intra-assay and inter-assay coefficients of variation of $2.7-4.8 \%$ and $3.6-5.5 \%$, respectively) were measured using in-house sandwich ELISA established in our laboratory (Antibody and Immunoassay Services [AIS], www.antibody.hku.hk). Details on the measurement of biochemical variables have been described previously [16]. Age, sex, smoking, drinking, drug medication and family history of diabetes were obtained using a standardised questionnaire. BMI was calculated as weight $(\mathrm{kg})$ divided by the square of height (m), and waist circumference was measured halfway between the xiphisternum and the umbilicus. Hypertension was defined as blood pressure $\geq 140 / 90 \mathrm{mmHg}$ or the use of antihypertensive medication. Regular drinking was defined as consumption of alcoholic drinks at least once a week.

Statistical analysis Statistical analysis was performed using SPSS 18.0 (SPSS Inc., Chicago, IL, USA). Data are presented as mean $\pm \mathrm{SD}$ or geometric mean $(95 \% \mathrm{CI})$. Variables with skewed distributions were log-transformed before analysis. Baseline characteristics were compared after adjusting for age and sex. Multiple Cox regression models were used to estimate the HR for the deterioration of glycaemia over a median of 5.4 years. Baseline variables were used as covariates in the regression model if they were biologically likely to affect glycaemia or were significantly different between participants with and without glycaemic progression. The improvement in model discrimination by the addition of hsCRP, adiponectin, or both as the independent variables was assessed by the log-likelihood ratio test and c-statistics (mathematically equivalent to areas under ROC [receiver operating characteristic] curves in binary outcomes) [18]. For variables that were highly correlated such as BMI and waist circumference, only one was entered into the regression analysis. The $p$ values for interaction were estimated by including each multiplicative interaction term in the multivariate regression models in full sample after adjusting for the main effects of all covariates.

\section{Results}

Table 1 shows the baseline clinical characteristics of participants with and without deterioration of glycaemia after a median interval of 5.4 years. A total of 134 and 17 participants with NGT at baseline had developed IFG/IGT and diabetes at follow-up, respectively, whereas 55 participants with IFG/IGT at baseline had developed diabetes at follow-up. There were 713 participants with NGT at both visits and 173 participants with IFG/IGT at both visits. A total of 196 participants with IFG/IGT at baseline reverted to NGT at follow-up. Participants with deterioration of glycaemia had significantly higher age, BMI, waist circumference, prevalence of hypertension, plasma triacylglycerols, $2 \mathrm{~h}$ post-OGTT glucose, fasting insulin, HOMA of insulin resistance index (HOMA-IR) and hsCRP level. The percentages of those taking lipid-lowering and antihypertensive medications were also higher in participants with deterioration of glycaemia. Participants with deterioration of glycaemia had significantly lower baseline adiponectin level in women, but not in men. There was no significant difference in fasting glucose.

In multiple Cox regression analysis (Table 2), only baseline age was a significant independent predictor of the deterioration of glycaemia, but not sex, BMI, hypertension, triacylglycerols, $2 \mathrm{~h}$ post-OGTT glucose and HOMA-IR (model 1). When baseline hsCRP and adiponectin levels were included in the model, they both showed significant association with the deterioration of glycaemia, together with baseline age (model 2). The same three independent predictors were observed if BMI was replaced by waist circumference in the regression model $(p<0.001$ for age, $p<0.001$ for hsCRP level and $p=0.007$ for adiponectin level). In a separate analysis, both hsCRP and adiponectin levels were still significant independent predictors, if HOMA-IR was replaced by fasting insulin $(p=0.001$ and 
Table 1 Baseline characteristics of participants with and without deterioration of glycaemia after a median interval of 5.4 years
Data are expressed as mean $\pm \mathrm{SD}$ unless stated otherwise

${ }^{a} 156$ individuals on antihypertensive medication were excluded

${ }^{\mathrm{b}}$ Data are expressed as geometric mean $(95 \% \mathrm{CI})$ due to skewed distributions

All $p$ values were adjusted for age and sex, except for age (adjusted for sex only) and sex (adjusted for age only)

\begin{tabular}{|c|c|c|c|}
\hline Baseline variable & $\begin{array}{l}\text { Without deterioration } \\
(n=1,082)\end{array}$ & $\begin{array}{l}\text { With deterioration } \\
(n=206)\end{array}$ & $p$ value \\
\hline Age (years) & $49.4 \pm 10.8$ & $53.5 \pm 10.9$ & $<0.001$ \\
\hline Women $(\%)$ & 55.5 & 52.9 & 0.761 \\
\hline BMI $\left(\mathrm{kg} / \mathrm{m}^{2}\right)$ & $23.7 \pm 3.3$ & $24.6 \pm 3.4$ & 0.001 \\
\hline Waist circumference (cm) & $78.3 \pm 9.5$ & $81.2 \pm 9.8$ & 0.001 \\
\hline Systolic blood pressure $(\mathrm{mmHg})^{\mathrm{a}}$ & $116.8 \pm 15.5$ & $120.6 \pm 16.9$ & 0.438 \\
\hline Diastolic blood pressure $(\mathrm{mmHg})^{\mathrm{a}}$ & $73.6 \pm 9.9$ & $74.9 \pm 9.6$ & 0.147 \\
\hline Hypertension $(\%)$ & 20.5 & 34.5 & 0.016 \\
\hline LDL-cholesterol (mmol/l) & $3.24 \pm 0.78$ & $3.37 \pm 0.83$ & 0.165 \\
\hline HDL-cholesterol (mmol/l) & $1.39 \pm 0.35$ & $1.39 \pm 0.35$ & 0.069 \\
\hline Triacylglycerols $(\mathrm{mmol} / \mathrm{l})^{\mathrm{b}}$ & $1.09(1.06,1.13)$ & $1.22(1.14,1.31)$ & 0.030 \\
\hline Fasting glucose $(\mathrm{mmol} / \mathrm{l})$ & $5.03 \pm 0.47$ & $5.13 \pm 0.50$ & 0.110 \\
\hline $2 \mathrm{~h}$ post-OGTT glucose $(\mathrm{mmol} / \mathrm{l})$ & $6.54 \pm 1.65$ & $7.02 \pm 1.60$ & 0.007 \\
\hline Fasting insulin $(\mathrm{pmol} / \mathrm{l})^{\mathrm{b}}$ & $48.9(47.4,50.5)$ & $54.8(51.1,58.9)$ & 0.004 \\
\hline HOMA-IR ${ }^{b}$ & $1.56(1.51,1.62)$ & $1.79(1.66,1.93)$ & 0.002 \\
\hline Family history of diabetes (\%) & 30.6 & 34.0 & 0.067 \\
\hline Adiponectin $(\mathrm{mg} / \mathrm{l})^{\mathrm{b}}$ & & & 0.002 \\
\hline Men & $5.69(5.39,6.00)$ & $5.72(5.08,6.44)$ & 0.268 \\
\hline Women & $8.04(7.69,8.41)$ & $6.78(6.20,7.86)$ & 0.001 \\
\hline hsCRP (mg/l) ${ }^{\mathrm{b}}$ & $0.60(0.56,0.64)$ & $0.89(0.78,1.02)$ & $<0.001$ \\
\hline Current smoking (\%) & 15.4 & 16.5 & 0.700 \\
\hline Regular drinking (\%) & 9.7 & 11.8 & 0.514 \\
\hline Lipid-lowering medication (\%) & 2.5 & 7.3 & 0.010 \\
\hline Antihypertensive medication (\%) & 10.4 & 21.4 & 0.004 \\
\hline
\end{tabular}

0.008 respectively). Figure 1 shows the percentage of participants with deterioration of glycaemia according to the baseline hsCRP and adiponectin levels.

In a Cox regression model with age, sex, BMI, hypertension, triacylglycerols, $2 \mathrm{~h}$ post-OGTT glucose and HOMA-IR (model A), the introduction of either biomarker, hsCRP or adiponectin level, or both could significantly improve the prediction of the deterioration of glycaemia (Table 3). The introduction of both hsCRP and adiponectin levels increased the c-statistics by 0.014 (Table 3). The introduction of hsCRP or adiponectin level to a model including the other biomarker resulted in a significant improvement in the prediction of glycaemic progression $(p<0.01$, see electronic supplementary material [ESM] Table 1). Similar results were obtained if BMI was replaced by waist circumference in the regression model (model B) or if HOMA-IR was replaced by fasting insulin (model C) (Table 3 and ESM Table 1).

There was no significant interaction between hsCRP and adiponectin levels in models $\mathrm{A}, \mathrm{B}$ and $\mathrm{C}$ ( $p$ for
Table 2 Multiple Cox regression analysis showing baseline variables independently associated with the deterioration of glycaemia over a median of 5.4 years

${ }^{\text {a }}$ Data were log-transformed before analysis and HRs are expressed in terms of per SD of log-transformed unit

\begin{tabular}{|c|c|c|c|c|}
\hline \multirow[t]{2}{*}{ Baseline variable } & \multicolumn{2}{|l|}{ Model 1} & \multicolumn{2}{|l|}{ Model 2} \\
\hline & $\operatorname{HR}(95 \% \mathrm{CI})$ & $p$ value & $\operatorname{HR}(95 \% \mathrm{CI})$ & $p$ value \\
\hline Age (years) & $1.03(1.02,1.05)$ & $<0.001$ & $1.03(1.02,1.05)$ & $<0.001$ \\
\hline Female sex & $1.06(0.80,1.41)$ & 0.689 & $1.15(0.86,1.55)$ & 0.349 \\
\hline BMI $\left(\mathrm{kg} / \mathrm{m}^{2}\right)$ & $1.02(0.98,1.07)$ & 0.308 & $0.99(0.95,1.04)$ & 0.781 \\
\hline Hypertension & $1.29(0.93,1.81)$ & 0.132 & $1.24(0.88,1.74)$ & 0.213 \\
\hline Triacylglycerols $(\mathrm{mmol} / \mathrm{l})^{\mathrm{a}}$ & $1.11(0.95,1.29)$ & 0.187 & $1.05(0.90,1.23)$ & 0.545 \\
\hline $2 \mathrm{~h}$ post-OGTT glucose $(\mathrm{mmol} / \mathrm{l})$ & $1.03(0.94,1.12)$ & 0.558 & $1.01(0.92,1.10)$ & 0.817 \\
\hline HOMA-IR ${ }^{\mathrm{a}}$ & $1.09(0.92,1.28)$ & 0.318 & $1.05(0.89,1.24)$ & 0.548 \\
\hline Adiponectin $(\mathrm{mg} / \mathrm{l})^{\mathrm{a}}$ & - & - & $0.80(0.68,0.95)$ & 0.008 \\
\hline $\mathrm{hsCRP}(\mathrm{mg} / \mathrm{l})^{\mathrm{a}}$ & - & - & $1.30(1.11,1.52)$ & 0.001 \\
\hline
\end{tabular}




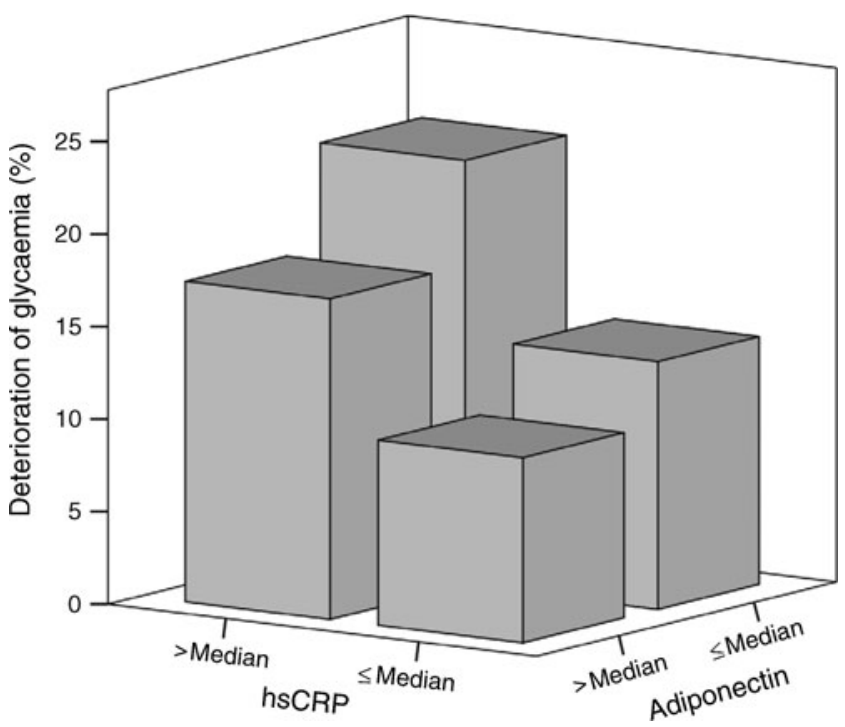

Fig. 1 A three-dimensional bar chart showing the percentage of participants with deterioration of glycaemia after a median interval of 5.4 years according to the baseline hsCRP and adiponectin levels. The median of hsCRP level was $0.66 \mathrm{mg} / \mathrm{l}$. As adiponectin level differed significantly with sex $(p<0.001)$, sex-specific median was used, which was $5.80 \mathrm{mg} / \mathrm{l}$ in men and $8.08 \mathrm{mg} / \mathrm{l}$ in women interaction >0.88). However, there was a trend of interaction between sex and adiponectin level with a marginally non-significant $p$ value of 0.06 in all the three models. Sex-specific analysis was therefore performed, showing that the greater predicted risks were largely contributed by the effects in women (ESM Table 1). In model A with hsCRP level, the improvement in the prediction by the introduction of adiponectin level did not reach statistical significance in men $(p=0.814)$. Similar results were obtained in models $\mathrm{B}$ and $\mathrm{C}$ (data not shown).

We then investigated whether the prediction of hsCRP and adiponectin levels differed between participants with NGT and IFG/IGT at baseline. Among participants with NGT at baseline, the introduction of hsCRP level, but not adiponectin level resulted in a significant improvement in the prediction of glycaemic progression (Table 4). In sexspecific analysis, the introduction of hsCRP, adiponectin or both levels resulted in a significant improvement in the prediction of glycaemic progression in women (c-statistics increased by $0.015-0.032$ ), but not in men (Table 4 ). In women, the introduction of hsCRP level to a model with adiponectin level could increase the likelihood ratio by 8.878 ( $p=0.003)$, whereas the introduction of adiponectin level to a model with hsCRP level could increase the

Table 3 Cox regression analysis of baseline hsCRP and adiponectin levels in the deterioration of glycaemia over a median of 5.4 years

\begin{tabular}{|c|c|c|c|c|c|c|}
\hline \multirow[t]{2}{*}{ Model } & \multirow[t]{2}{*}{ Baseline variable } & \multicolumn{2}{|l|}{ HR $(95 \%$ CI $)$} & \multirow[t]{2}{*}{ Likelihood ratio } & \multirow[t]{2}{*}{$p$ value } & \multirow[t]{2}{*}{ c-statistic } \\
\hline & & hsCRP & Adiponectin & & & \\
\hline \multicolumn{7}{|c|}{ Model A } \\
\hline Null & No hsCRP and adiponectin & - & - & - & - & 0.541 \\
\hline 1 & $+\mathrm{hsCRP}$ & $1.32(1.13,1.55)$ & - & $12.291^{\mathrm{a}}$ & $<0.001$ & 0.551 \\
\hline 2 & + adiponectin & - & $0.79(0.67,0.92)$ & $8.356^{\mathrm{a}}$ & 0.004 & 0.546 \\
\hline 3 & + hsCRP + adiponectin & $1.30(1.11,1.52)$ & $0.80(0.68,0.95)$ & $19.108^{\mathrm{b}}$ & $<0.001$ & 0.555 \\
\hline \multicolumn{7}{|c|}{ Model B } \\
\hline Null & No hsCRP and adiponectin & - & - & - & - & 0.539 \\
\hline 1 & + hsCRP & $1.35(1.15,1.57)$ & - & $14.121^{\mathrm{a}}$ & $<0.001$ & 0.550 \\
\hline 2 & + adiponectin & - & $0.78(0.66,0.92)$ & $8.965^{\mathrm{a}}$ & 0.003 & 0.544 \\
\hline 3 & + hsCRP + adiponectin & $1.32(1.13,1.54)$ & $0.80(0.68,0.94)$ & $21.162^{b}$ & $<0.001$ & 0.553 \\
\hline \multicolumn{7}{|c|}{ Model C } \\
\hline Null & No hsCRP and adiponectin & - & - & - & - & 0.541 \\
\hline 1 & + hsCRP & $1.32(1.13,1.54)$ & - & $11.929^{\mathrm{a}}$ & 0.001 & 0.551 \\
\hline 2 & + adiponectin & - & $0.79(0.67,0.92)$ & $8.312^{\mathrm{a}}$ & 0.004 & 0.546 \\
\hline 3 & + hsCRP + adiponectin & $1.30(1.11,1.52)$ & $0.80(0.68,0.94)$ & $18.807^{\mathrm{b}}$ & $<0.001$ & 0.554 \\
\hline
\end{tabular}

Model A: Age, sex, BMI, hypertension, triacylglycerols, $2 \mathrm{~h}$ post-OGTT glucose and HOMA-IR were included

Model B: BMI in model A was replaced by waist circumference

Model C: HOMA-IR in model A was replaced by fasting insulin

Triacylglycerols, HOMA-IR, insulin, hsCRP and adiponectin levels were log-transformed before analysis. HRs are expressed in terms of per SD of log-transformed unit

${ }^{\text {a }}$ Models 1 and 2 were compared with the null model by $\chi^{2} \quad(d f=1)$

${ }^{\mathrm{b}}$ Model 3 was compared with the null model by $\chi^{2}(d f=2)$ 
Table 4 Cox regression analysis of baseline hsCRP and adiponectin levels in the change of glycaemia over a median of 5.4 years according to the glycaemic status at baseline

\begin{tabular}{|c|c|c|c|c|c|c|c|}
\hline \multirow[t]{2}{*}{ Variable } & \multirow[t]{2}{*}{ Model } & \multirow[t]{2}{*}{ Baseline variables } & \multicolumn{2}{|l|}{$\operatorname{HR}(95 \% \mathrm{CI})$} & \multirow[t]{2}{*}{ Likelihood ratio } & \multirow[t]{2}{*}{$p$ value } & \multirow[t]{2}{*}{ c-statistic } \\
\hline & & & hsCRP & Adiponectin & & & \\
\hline \multicolumn{8}{|c|}{$\mathrm{NGT} \rightarrow \mathrm{NGT}($ control, $n=713$ ) vs NGT $\rightarrow \mathrm{IFG} / \mathrm{IGT} /$ diabetes (case, $n=151$ ) } \\
\hline \multirow[t]{4}{*}{ Overall $(n=864)$} & Null & No hsCRP and adiponectin & - & - & - & - & 0.621 \\
\hline & 1 & + hsCRP & $1.27(1.05,1.52)$ & - & $6.375^{\mathrm{a}}$ & 0.012 & 0.628 \\
\hline & 2 & + Adiponectin & - & $0.86(0.71,1.04)$ & $2.468^{\mathrm{a}}$ & 0.116 & 0.621 \\
\hline & 3 & + hsCRP+adiponectin & $0.87(0.72,1.05)$ & $1.26(1.05,1.51)$ & $8.460^{\mathrm{b}}$ & 0.015 & 0.628 \\
\hline \multirow[t]{4}{*}{ Men $(n=363)$} & Null & No hsCRP and adiponectin & - & - & - & - & 0.658 \\
\hline & 1 & + hsCRP & $1.19(0.92,1.54)$ & - & $1.855^{\mathrm{a}}$ & 0.173 & 0.660 \\
\hline & 2 & + Adiponectin & - & $1.81(0.86,1.62)$ & $1.073^{\mathrm{a}}$ & 0.300 & 0.664 \\
\hline & 3 & + hsCRP+adiponectin & $1.20(0.88,1.64)$ & $1.21(0.93,1.56)$ & $3.145^{\mathrm{b}}$ & 0.208 & 0.666 \\
\hline \multirow[t]{4}{*}{ Women $(n=501)$} & Null & No hsCRP and adiponectin & - & - & - & - & 0.610 \\
\hline & 1 & + hsCRP & $1.34(1.03,1.74)$ & - & $4.762^{\mathrm{a}}$ & 0.029 & 0.626 \\
\hline & 2 & + Adiponectin & - & $0.70(0.56,0.88)$ & $8.653^{\mathrm{a}}$ & 0.003 & 0.625 \\
\hline & 3 & + hsCRP+adiponectin & $1.35(1.04,1.75)$ & $0.70(0.56,0.88)$ & $13.641^{\mathrm{b}}$ & 0.001 & 0.642 \\
\hline \multicolumn{8}{|c|}{$\mathrm{IFG} / \mathrm{IGT} \rightarrow \mathrm{IFG} / \mathrm{IGT}($ control, $n=173$ ) vs $\mathrm{IFG} / \mathrm{IGT} \rightarrow$ diabetes $($ case, $n=55)$} \\
\hline & Null & No hsCRP and adiponectin & - & - & - & - & 0.544 \\
\hline & 1 & + hsCRP & $1.09(0.81,1.45)$ & - & $0.317^{\mathrm{a}}$ & 0.573 & 0.544 \\
\hline & 2 & + Adiponectin & - & $0.73(0.53,1.01)$ & $3.528^{\mathrm{a}}$ & 0.060 & 0.555 \\
\hline & 3 & + hsCRP+adiponectin & $1.05(0.79,1.41)$ & $0.74(0.54,1.02)$ & $3.643^{\mathrm{b}}$ & 0.162 & 0.555 \\
\hline \multicolumn{8}{|c|}{$\mathrm{IFG} / \mathrm{IGT} \rightarrow \mathrm{IFG} / \mathrm{IGT}($ control, $n=173$ ) vs $\mathrm{IFG} / \mathrm{IGT} \rightarrow \mathrm{NGT}($ case, $n=196)$} \\
\hline & Null & No hsCRP and adiponectin & - & - & - & - & 0.574 \\
\hline & 1 & + hsCRP & $1.04(0.89,1.21)$ & - & $0.252^{\mathrm{a}}$ & 0.616 & 0.572 \\
\hline & 2 & + Adiponectin & - & $0.93(0.78,1.10)$ & $0.672^{\mathrm{a}}$ & 0.412 & 0.573 \\
\hline & 3 & + hsCRP + adiponectin & $1.04(0.89,1.21)$ & $0.93(0.79,1.11)$ & $0.903^{\mathrm{b}}$ & 0.637 & 0.571 \\
\hline
\end{tabular}

Age, sex (except in sex-specific subgroups), BMI, hypertension, triacylglycerols, $2 \mathrm{~h}$ post-OGTT glucose and HOMA-IR were included in all models

Triacylglycerols, HOMA-IR, insulin, hsCRP, and adiponectin levels were log-transformed before analysis. HRs are expressed in term of per SD of log-transformed unit

${ }^{\mathrm{a}}$ Models 1 and 2 were compared with the null model by $\chi^{2}(d f=1) ;{ }^{\mathrm{b}}$ model 3 was compared with the null model by $\chi^{2}(d f=2)$

likelihood ratio by 4.987 ( $p=0.026)$. On the other hand, among participants with IFG/IGT at baseline, the introduction of hsCRP, adiponectin or both levels could not improve the prediction of glycaemic progression from IFG/IGT to diabetes significantly (Table 4). As the number of participants with glycaemic progression was small, we assessed the glycaemic improvement among participants with IFG/IGT at baseline. In this separate analysis, the introduction of hsCRP, adiponectin or both levels still could not improve the prediction of glycaemic improvement significantly (Table 4). In both analyses of participants with IFG/IGT at baseline, similar non-significant results were obtained in sex-specific analysis (data not shown). In all these analysis, similar results were obtained if BMI was replaced by waist circumference in the Cox regression models or if HOMA-IR was replaced by fasting insulin (data not shown).

\section{Discussion}

This report is the first study to evaluate the combined use of hsCRP and total adiponectin on the prediction of glycaemic progression in Chinese. In this study, raised hsCRP and reduced adiponectin levels were found to be associated with glycaemic progression, consistent with what we and others have previously reported $[6-8,10$ 12]. We also further demonstrated, in a general population, that their usefulness as independent biomarkers for predicting the deterioration of glycaemia, over a median interval of 5.4 years, was over and above those of conventional risk factors such as age, sex, BMI, insulin resistance and baseline $2 \mathrm{~h}$ post-OGTT glucose. Furthermore, we have shown that the combined use of these two biomarkers resulted in an improvement in risk prediction, compared with the use of either on its own, especially in 
women, but not in participants with IFG/IGT at baseline. Therefore, the combined use of hsCRP and adiponectin levels can help to identify participants at higher future risk of deterioration of glycaemia and type 2 diabetes in Chinese people, especially in women with NGT. Our findings also highlight the role of adiposity-related inflammation in the development of type 2 diabetes.

Adiponectin possesses anti-inflammatory properties [2, 3]. Previous cell culture studies have shown that adiponectin can suppress CRP synthesis and secretion from aortic endothelial cells and hepatocytes [19]. On the other hand, CRP can also suppress adiponectin expression and secretion from adipocytes [20]. In our population, adiponectin level correlates negatively with hsCRP level [21]. However, in this study, we did not find any interaction between hsCRP and adiponectin levels on the deterioration of glycaemia.

The independent effect of hsCRP and adiponectin levels on glycaemia is consistent with some previous studies. For example, the metabolic syndrome is a risk factor of type 2 diabetes [16] and hypoadiponectinaemia is associated with prevalent metabolic syndrome independent of age, sex, BMI and fasting insulin [22], or even after adjusting for inflammatory markers such as hsCRP level [23]. In a cross-sectional Japanese study, both hsCRP and high molecular weight (HMW) adiponectin (the active form of adiponectin) levels showed independent effect in the association with the metabolic syndrome [24]. In another Japanese study, the ratio of hsCRP to HMW adiponectin levels was more associated with insulin resistance than either hsCRP or HMW adiponectin level alone [25]. However, hypoadiponectinaemia, but not raised hsCRP level, predicted future risk of type 2 diabetes in Pima Indians [26], and the association of hsCRP level with incident diabetes could be contributed at least partly by adiponectin level in a study of white people [15]. There is only one previous study that investigated the combined effect of hsCRP and adiponectin levels on the risk of developing diabetes. In that Aboriginal Canadian study, hypoadiponectinaemia, but not raised hsCRP level, predicted incident type 2 diabetes and their combination did not improve diabetes prediction [27]. However, in that study, $22.2 \%$ of participants had their diabetes outcome obtained from self-reported questionnaire. The discrepancy between these and our study could be partly attributed to the differences in study power and characteristics of the study participants. Nevertheless, the predictive ability of hsCRP level seems to be stronger in Asian than in white people, whereas adiponectin level gives good prediction in both ethnicities. In fact, adiposity and insulin resistance have been found to be the major confounding factors, together with age, smoking and hypertension for the prediction of hsCRP levels with incident diabetes or glycaemic progression in whites, Aboriginal Canadians and Pima Indians [15, 26-30]. In our study, these confounding factors were not associated with glycaemic progression, except age. This difference could be attributed to the ethnic differences in visceral adiposity and hsCRP level $[13,14]$. It has been reported that Chinese people have a greater amount of visceral adipose tissue than whites and this difference does not exist between white people and Aboriginal Canadians [31]. Even among Asians, the association of hsCRP level with IFG or elevated level of glycated haemoglobin is stronger in Chinese people than in Malay and Indian non-diabetic individuals [32].

In our study, the independent effect of hsCRP and adiponectin levels was only found in women, but not in men. This may be partly due to the sex difference in the pattern of fat accumulation and greater effect of body fat on subclinical inflammation in women [33]. Moreover, raised levels of inflammatory markers such as hsCRP and IL-6 are more predictive of future risk of type 2 diabetes in women than in men [34]. As the progression from NGT to IFG/IGT or diabetes mellitus may not be the same as that from IFG/ IGT to diabetes mellitus, we also investigated the combination effect of hsCRP and adiponectin levels according to the baseline glycaemic status. In this analysis, neither hsCRP nor adiponectin levels showed independent effect among participants with IFG/IGT at baseline. The improvement in risk prediction with the combined use of these two biomarkers was more prominent in women with NGT at baseline. The reason for this is speculative. Subjects with IFG/IGT already have elevated hsCRP and reduced adiponectin levels. Therefore, these variables may not have the ability to predict the further changes in glycaemic status. Moreover, the situation may also be further complicated by the finding of a recent study, showing that hyperglycaemia could increase CRP secretion from human macrophages [35].

Our study was limited by the relatively small number of participants with the deterioration of glycaemia as the participants were recruited from the general population. However, this is the largest prospective study investigating the combined effect of hsCRP and adiponectin levels on glycaemia. As there are ethnic differences in visceral adiposity, hsCRP levels and prediction of hsCRP for glycaemic progression [13, 14, 31, 32], our findings may not be generalised to populations of other ethnicities and may need to be confirmed in other independent cohorts with larger sample size and different ethnic groups.

In conclusion, adiponectin and hsCRP levels independently predict the deterioration of glycaemia. Using both biomarkers improves the prediction, especially in women, but not in participants with IFG/NGT. 
Acknowledgements This study was funded by Hong Kong Research Grants Council grants (HKU7229/01 M and HKU7626/ $07 \mathrm{M})$ and the Sun Chieh Yeh Heart Foundation. K. L. Ong was supported by a grant from the National Health and Medical Research Council of Australia (grant 482800).

K.L.O. contributed to conception and design, analysis and interpretation of data and manuscript drafting. A.W.K.T., B.M.Y.C. and K.S.L.L. contributed to conception and design, acquisition of funding and manuscript revision. A.X. contributed to conception and design, biomarker measurement and manuscript revision. L.S.C.L. contributed to analysis and interpretation of data, and manuscript revision. M.L. contributed to conception and design, biomarker measurement, data collection and manuscript revision. N.M.S.W., K.A.R. and T.H.L. contributed to conception and design, and manuscript revision. All authors have approved the final version of the manuscript to be published.

Duality of interest The authors declare that there is no duality of interest associated with this manuscript.

Open Access This article is distributed under the terms of the Creative Commons Attribution Noncommercial License which permits any noncommercial use, distribution, and reproduction in any medium, provided the original author(s) and source are credited.

\section{References}

1. Després JP, Lemieux I (2006) Abdominal obesity and metabolic syndrome. Nature 444:881-887

2. Tso AW, Xu A, Chow WS, Lam KS (2008) Adipose tissue and the metabolic syndrome: focusing on adiponectin and several novel adipokines. Biomark Med 2:239-252

3. Li FY, Cheng KK, Lam KS, Vanhoutte PM, Xu A (2010) Crosstalk between adipose tissue and vasculature: role of adiponectin. Acta Physiol (Oxf). doi:10.1111/j.1748-1716.2010.02216.x

4. Arita Y, Kihara S, Ouchi N et al (1999) Paradoxical decrease of an adipose-specific protein, adiponectin, in obesity. Biochem Biophys Res Commun 257:79-83

5. Hotta K, Funahashi T, Arita Y et al (2000) Plasma concentrations of a novel, adipose-specific protein, adiponectin, in type 2 diabetic patients. Arterioscler Thromb Vasc Biol 20:1595-1599

6. Tso AW, Sham PC, Wat NM et al (2006) Polymorphisms of the gene encoding adiponectin and glycaemic outcome of Chinese subjects with impaired glucose tolerance: a 5-year follow-up study. Diabetologia 49:1806-1815

7. Lindsay RS, Funahashi T, Hanson RL et al (2002) Adiponectin and development of type 2 diabetes in the Pima Indian population. Lancet 360:57-58

8. Spranger J, Kroke A, Möhlig M et al (2004) Adiponectin and protection against type 2 diabetes mellitus. Lancet 361:226-228

9. Lemieux I, Pascot A, Prud'homme D et al (2001) Elevated Creactive protein: another component of the atherothrombotic profile of abdominal obesity. Arterioscler Thromb Vasc Biol 21:961-967

10. Tan KC, Wat NM, Tam SC, Janus ED, Lam TH, Lam KS (2003) C-reactive protein predicts the deterioration of glycemia in Chinese subjects with impaired glucose tolerance. Diabetes Care 26:2323-2328

11. Pradhan AD, Manson JE, Rifai N, Buring JE, Ridker PM (2001) C-reactive protein, interleukin 6 , and risk of developing type 2 diabetes mellitus. JAMA 286:327-334

12. Barzilay JI, Abraham L, Heckbert SR et al (2001) The relation of markers of inflammation to the development of glucose disorders in the elderly: the Cardiovascular Health Study. Diabetes 50:2384-2389

13. Cheung BM, Thomas GN (2007) The metabolic syndrome and vascular disease in Asia. Cardiovasc Hematol Disord Drug Targets 7:79-85

14. Kelley-Hedgepeth A, Lloyd-Jones DM, Colvin A et al (2008) Ethnic differences in C-reactive protein concentrations. Clin Chem 54:1027-1037

15. Lee CC, Adler AI, Sandhu MS et al (2009) Association of Creactive protein with type 2 diabetes: prospective analysis and meta-analysis. Diabetologia 52:1040-1047

16. Cheung BM, Wat NM, Man YB et al (2007) Development of diabetes in Chinese with the metabolic syndrome: a 6-year prospective study. Diabetes Care 30:1430-1436

17. American Diabetes Association (2007) Standards of medical care in diabetes-2007. Diabetes Care 30:S4-S41

18. Harrell FE Jr, Lee KL, Mark DB (1996) Multivariable prognostic models: issues in developing models, evaluating assumptions and adequacy, and measuring and reducing errors. Stat Med 15:361387

19. Devaraj S, Torok N, Dasu MR, Samols D, Jialal I (2008) Adiponectin decreases C-reactive protein synthesis and secretion from endothelial cells: evidence for an adipose tissue-vascular loop. Arterioscler Thromb Vasc Biol 28:1368-1374

20. Yuan G, Chen X, Ma Q et al (2007) C-reactive protein inhibits adiponectin gene expression and secretion in 3 T3-L1 adipocytes. J Endocrinol 194:275-281

21. Ong KL, Li M, Tso AW et al (2010) Association of genetic variants in the adiponectin gene with adiponectin level and hypertension in Hong Kong Chinese. Eur J Endocrinol 163:251257

22. Hung J, McQuillan BM, Thompson PL, Beilby JP (2008) Circulating adiponectin levels associate with inflammatory markers, insulin resistance and metabolic syndrome independent of obesity. Int J Obes (Lond) 32:772-779

23. Matsushita K, Yatsuya H, Tamakoshi K et al (2006) Comparison of circulating adiponectin and proinflammatory markers regarding their association with metabolic syndrome in Japanese men. Arterioscler Thromb Vasc Biol 26:871-876

24. Tabara Y, Osawa H, Kawamoto R et al (2008) Reduced highmolecular-weight adiponectin and elevated high-sensitivity Creactive protein are synergistic risk factors for metabolic syndrome in a large-scale middle-aged to elderly population: the Shimanami Health Promoting Program Study. J Clin Endocrinol Metab 93:715-722

25. Saisho Y, Hirose H, Seino Y, Saito I, Itoh H (2010) Usefulness of C-reactive protein to high-molecular-weight adiponectin ratio to predict insulin resistance and metabolic syndrome in Japanese men. J Atheroscler Thromb 17:944-952

26. Krakoff J, Funahashi T, Stehouwer CD et al (2003) Inflammatory markers, adiponectin, and risk of type 2 diabetes in the Pima Indian. Diabetes Care 26:1745-1751

27. Ley SH, Harris SB, Connelly PW et al (2008) Adipokines and incident type 2 diabetes in an Aboriginal Canadian population: the Sandy Lake Health and Diabetes Project. Diabetes Care 31:1410 1415

28. Thorand B, Löwel H, Schneider A et al (2003) C-reactive protein as a predictor for incident diabetes mellitus among middle-aged men: results from the MONICA Augsburg cohort study, 19841998. Arch Intern Med 163:93-99

29. Duncan BB, Schmidt MI, Pankow JS et al (2003) Low-grade systemic inflammation and the development of type 2 diabetes: the atherosclerosis risk in communities study. Diabetes 52:1799-1805

30. Festa A, D'Agostino R Jr, Tracy RP, Haffner SM; Insulin Resistance Atherosclerosis Study (2002) Elevated levels of acute-phase proteins and plasminogen activator inhibitor-1 predict 
the development of type 2 diabetes: the insulin resistance atherosclerosis study. Diabetes 51:1131-1137

31. Lear SA, Humphries KH, Kohli S, Chockalingam A, Frohlich JJ, Birmingham CL (2007) Visceral adipose tissue accumulation differs according to ethnic background: results of the Multicultural Community Health Assessment Trial (M-CHAT). Am J Clin Nutr $86: 353-359$

32. Sabanayagam C, Shankar A, Lim SC, Lee J, Tai ES, Wong TY (2011) Serum C-reactive protein level and prediabetes in two Asian populations. Diabetologia 54:767-775
33. Khera A, Vega GL, Das SR et al (2009) Sex differences in the relationship between C-reactive protein and body fat. J Clin Endocrinol Metab 94:3251-3258

34. Thorand B, Baumert J, Kolb H et al (2007) Sex differences in the prediction of type 2 diabetes by inflammatory markers: results from the MONICA/KORA Augsburg case-cohort study, 19842002. Diabetes Care 30:854-860

35. Kaplan M, Tendler Y, Mahamid R, Shiner M, Aviram M, Hayek T (2010) High glucose upregulates C-reactive protein synthesis in macrophages. Clin Chem 56:1036-1038 